Article

\title{
Combined Treatment of Heteronemin and Tetrac Induces Antiproliferation in Oral Cancer Cells
}

\author{
Chi-Hung Huang ${ }^{1,2}$, Tung-Yung Huang ${ }^{3,4}$, Wong-Jin Chang ${ }^{3}$, Yi-shin Pan ${ }^{3,4}$, Hung-Ru Chu ${ }^{3,4}$,

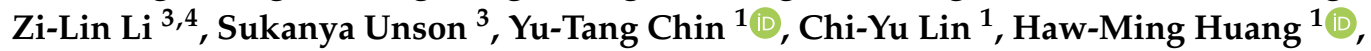 \\ Chao-Nan Hsiung ${ }^{5}$, Fabio Gionfra ${ }^{6}$, Paolo De Vito ${ }^{7}$, Jens Z. Pedersen ${ }^{7} \mathbb{1}$, Sandra Incerpi ${ }^{6} \mathbb{( \mathbb { D }}$, \\ Yi-Ru Chen ${ }^{4}$, Sheng-Yang Lee ${ }^{1,8, *}$, Hung-Yun Lin ${ }^{3,9,10,11}$, Paul J. Davis 9,12 ${ }^{\mathbb{D}}$, \\ Jacqueline Whang-Peng ${ }^{3,10}$ and Kuan Wang ${ }^{4}$ \\ 1 School of Dentistry, College of Oral Medicine, Taipei Medical University, Taipei 11031, Taiwan; \\ hchbox@cgh.org.tw (C.-H.H.); yutangchin@gmail.com (Y.-T.C.); alexlin1018@gmail.com (C.-Y.L.); \\ hhm@tmu.edu.tw (H.-M.H.) \\ 2 Division of Cardiology, Department of Internal Medicine, Cathay General Hospital, Taipei 10630, Taiwan \\ 3 Graduate Institute of Cancer Biology and Drug Discovery, College of Medical Science and Technology, Taipei \\ Medical University, Taipei 11031, Taiwan; charvel0203@gmail.com (T.-Y.H.); wjchang@tmu.edu.tw (W.-J.C.); \\ extraganoderma@gmail.com (Y.-s.P.); a0918362166@tmu.edu.tw (H.-R.C.); lizilin0919@gmail.com (Z.-L.L.); \\ sukanya_unson@hotmail.com (S.U.); linhy@tmu.edu.tw (H.-Y.L.); jqwpeng@nhri.org.tw (J.W.-P.) \\ 4 Graduate Institute of Nanomedicine and Medical Engineering, College of Medical Engineering, Taipei \\ Medical University, Taipei 11031, Taiwan; aquarlus9132@gmail.com (Y.-R.C.); wangk007@gmail.com (K.W.) \\ 5 College of Medical Science and Technology, Taipei Medical University, Taipei 11031, Taiwan; \\ juanita@tmu.edu.tw \\ 6 Department of Sciences, University Roma Tre, 00146 Rome, Italy; fabio.gionfra@uniroma3.it (F.G.); \\ sandra.incerpi@uniroma3.it (S.I.) \\ 7 Department of Biology, University of Rome Tor Vergata, 00133 Rome, Italy; \\ Paolo.De.Vito@uniroma2.it (P.D.V.); j.z.pedersen@gmail.com (J.Z.P.) \\ 8 Department of Dentistry, Wan-Fang Medical Center, Taipei Medical University, Taipei 11031, Taiwan \\ 9 Pharmaceutical Research Institute, Albany College of Pharmacy and Health Sciences, \\ Albany, NY 12208, USA; pdavis.ordwayst@gmail.com \\ 10 Cancer Center, Wan-Fang Medical Center, Taipei Medical University, Taipei 11696, Taiwan \\ 11 TMU Research Center of Cancer Translational Medicine, Taipei Medical University, Taipei 11031, Taiwan \\ 12 Albany Medical College, Albany, NY 12208, USA \\ * Correspondence: seanlee@tmu.edu.tw; Tel.: +886-2-2736-1661
}

Received: 5 June 2020; Accepted: 28 June 2020; Published: 2 July 2020

check for updates

\begin{abstract}
Background: Heteronemin, a marine sesterterpenoid-type natural product, possesses an antiproliferative effect in cancer cells. In addition, heteronemin has been shown to inhibit $p 53$ expression. Our laboratory has demonstrated that the thyroid hormone deaminated analogue, tetrac, activates $p 53$ and induces antiproliferation in colorectal cancer. However, such drug mechanisms are still to be studied in oral cancer cells. Methods: We investigated the antiproliferative effects by Cell Counting Kit- 8 and flow cytometry. The signal transduction pathway was measured by Western blotting analyses. Quantitative PCR was used to evaluate gene expression regulated by heteronemin, 3,3',5,5'-tetraiodothyroacetic acid (tetrac), or their combined treatment in oral cancer cells. Results: Heteronemin inhibited not only expression of proliferative genes and Homo Sapiens Thrombospondin 1 (THBS-1) but also cell proliferation in both OEC-M1 and SCC-25 cells. Remarkably, heteronemin increased TGF- $\beta 1$ expression in SCC-25 cells. Tetrac suppressed expression of THBS-1 but not $p 53$ expression in both cancer cell lines. Furthermore, the synergistic effect of tetrac and heteronemin inhibited ERK1/2 activation and heteronemin also blocked STAT3 signaling. Combined treatment increased p53 protein and p53 activation accumulation although heteronemin inhibited p53 expression in both cancer cell lines. The combined treatment induced antiproliferation synergistically more than a single agent. Conclusions: Both heteronemin and tetrac inhibited ERK1/2 activation and
\end{abstract}


increased 553 phosphorylation. They also inhibited THBS-1 expression. Moreover, tetrac suppressed TGF- $\beta$ expression combined with heteronemin to further enhance antiproliferation and anti-metastasis in oral cancer cells.

Keywords: tetrac; heteronemin; oral cancer; antiproliferation

\section{Introduction}

Oral cancer is a fatal disease, and its incidence is increasing in Taiwan [1]. It accounts for the fourth-highest incidence of malignancy in males and the seventh-highest in the general population of Taiwan [2]. About 95\% of oral cancer in Taiwan is oral squamous cell carcinoma (OSCC). Regrettably, about $50 \%$ of new OSCC cases presenting to medical centers are stage III or IV cancer lesions. Those patients have a low 5-year survival rate [1]. Current treatments of oral cancer vary depending on the type, location, and stage of cancer at diagnosis. Treatment of the early stages of oral cancer generally is surgery or radiation therapy. Advanced-stage treatment is usually a combination of chemotherapy and radiation therapy which is demonstrated to be more effective for cancer treatment than a single drug. Therefore, searching for novel oral cancer therapies with low side effects might be an important issue in oral cancer therapy.

Heteronemin is a spongean sesterterpenoid, which acts against different kinds of cancers [2,3] with low or non-cytotoxicity to non-malignant cells [4,5]. Heteronemin potently inhibits anchorage-independent growth of human prostate cancer cells [6]. It activates both extrinsic caspase (CASP)-8- and intrinsic caspase-9-dependent pathways in prostate cancer cells to induce apoptosis [6]. Heteronemin directly generates reactive oxygen species (ROS) to induce oxidative stress, which induces phosphorylated talin and promotes antiproliferation in cancer cells [3], but it does not disrupt talin/focal adhesion kinase (FAK) complex formation. In addition, heteronemin can cause morphological changes via interfering with actin microfilaments [3]. Heteronemin is shown to prevent phosphorylation of c-Met/Src/signal transducer and activator of transcription 3 (STAT3) [6]. Furthermore, it suppresses expression of STAT3-regulated genes such as $B c l-x L, B c l-2$, and cyclin D1 [2]. It efficiently antagonizes hepatocyte growth factor (HGF)-stimulated c-Met/STAT3 activation, and the proliferation and colony formation of refractory prostate cancer cells [6]. Our results indicated that heteronemin concurrently inhibits TGF- $\beta$ expression with antiproliferation, anti-migration, and anti-adhesion effects [2]. On the other hand, heteronemin inhibits p53 expression and activity in cholangiocarcinomas [2].

The thyroid hormone deaminated analog, 3,3',5,5'-tetraiodothyroacetic acid (tetrac), inhibits cancer cell growth in vitro and in animal xenografts $[7,8]$ and also has been shown to have no cytotoxicity to non-malignant cells [9]. It induces antiproliferation as well as anti-angiogenesis and anti-metastasis [7,8] via activating expression of pro-apoptotic genes such as $p 53, p 21$, and CBY1. It also suppresses the expression of proliferative genes. It has shown to activate Homo Sapiens Thrombospondin 1 (THBS-1) which is anti-angiogenic in MDA-MB-231 and colorectal cancer HCT-116 cells. Cross-talk between different signal transduction pathways plays a critical role in cancer development and therapeutic resistance. Tetrac and nano-diamino-tetrac (NDAT) were shown to inhibit K-RAS-mutant cancer cell growth in colorectal cancer and lung cancer [9-11]. They are able to compensate for a lack of therapeutic efficacy in gefitinib- and cetuximab-resistant colorectal cancer cells $[9,11,12]$.

Against this background, we investigated mechanisms of how tetrac potentiates anti-cancer growth induced by heteronemin in oral cancer cells. Results reported here indicate that heteronemin induces antiproliferation in oral cancer cells by inhibiting activation of extracellular signal-regulated kinase 1/2 (ERK1/2) and STAT3. Heteronemin suppressed expression of proliferative genes, THBS-1 and $p 53$, but not p53 protein accumulation. It also suppressed TGF- $\beta$ expression in OEC-M1 cells but not in SCC-25 cells. On the other hand, tetrac enhanced heteronemin-induced antiproliferation via inhibiting ERK1/2 activation. It further inhibited expression of THBS-1 in both cancer cell lines. Tetrac 
suppressed TGF- $\beta$ expression in combination with heteronemin. It promoted p53 phosphorylation in combination with heteronemin. The mechanisms implicated in the combined treatment of tetrac and heteronemin showed a synergistic antiproliferative effect.

\section{Results}

\subsection{Heteronemin Induces Antiproliferation and Modulates Gene Expression in Different Types of Oral Cancer Cells}

Heteronemin has been shown to induce antiproliferation in human cholangiocarcinoma cells and various cancer cells [2]. It has been shown to suppress expression of TGF- $\beta$ and p53 in cholangiocarcinoma [2]. Studies were conducted to examine the growth inhibition of heteronemin in two different types of oral cancer cells. OEC-M1 or SCC-25 cells were treated with different concentrations of heteronemin for 24,48 , and $72 \mathrm{~h}$. Then the Cell Counting Kit- 8 reagent was added to detect the cytoxicity after treatment (Figure 1). In the time-course experiment, heteronemin caused a significant cytotoxic effect in both oral cancer cell lines, starting at $0.313 \mu \mathrm{M}$, in a dose-dependent manner (Figure 1A,B). Furthermore, prolonged treatment increased the cytotoxic effect of herteronemin. The inhibitory rate for each concentration is shown in Figures in the appendix. To further understand the mechanisms involved in heteronemin-induced antiproliferation, SCC-25 cells were treated with different concentrations of heteronemin for $24 \mathrm{~h}$ and harvested for a flow cytometric assay (Figure 1C). Low concentration of heteronemin treatment $(0.313 \mu \mathrm{M})$ mildly increased the cell population in G0/G1 phase and decreased the cell population in $\mathrm{S}$ and G2/M phase. With increasing concentration of heteronemin, there was cell phase arrest in the $\mathrm{G} 2 / \mathrm{M}$ phase $(0.625 \mu \mathrm{M})$ and drastically increased sub-G0/G1 population at the highest concentration of heteronemin $(1.25 \mu \mathrm{M})$. These results suggest that heteronemin may activate different pathways to induce antiproliferation at different concentrations.

To investigate the potential mechanism of heteronemin-induced antiproliferation in oral cancer cells, we further studied the effect of heteronemin on gene expression in OEC-M1 and SCC-25 cells. Overall, heteronemin suppressed expression of $p 53, P C N A$, and THSB- 1 starting significantly at $0.313 \mu \mathrm{M}$ in a concentration-dependent manner, except for CCND1 in OEC-M1 cells (Figure 2). The pro-apoptotic p21 expression was enhanced by heteronemin in a dose-dependent manner. Following the expression of PCNA and CCND1, these changes suggest that the cell cycle of OEC-M1 is indeed inhibited by heteronemin. TGF- $\beta 1$ expression was only inhibited by heteronemin at $1.25 \mu \mathrm{M}$.

Moreover, the same genes were examined in another oral cancer cell line, SCC-25 cells. The qPCR results indicated that heteronemin attenuated expression of the proliferative gene, PCNA, and CCND1, at $0.313 \mu \mathrm{M}$, but it was not much more effective as the concentration increased. This situation was also observed in $p 53$ and THBS-1. The expression of $p 21$ was increased dose-dependently by heteronemin in SCC-25 as well as OEC-M1. Unlike OEC-M1, heteronemin stimulated high expression of TGF- $\beta 1$ starting at $0.625 \mu \mathrm{M}$.

Although heteronemin induced antiproliferation in two oral cancer cell lines, it suppressed p53 expression in both cancer cell lines and induced TGF- $\beta$ expression in SCC-25 cells. Tetrac has been shown to activate $p 53$ expression [10] and inhibit TGF- $\beta$ expression [13]. Additionally, thyroid hormone stimulates TGF- $\beta$ expression in oral cancer cells [14] which can be inhibited by tetrac. Thus, the combined treatment of tetrac and heteronemin might compensate for heteronemin-induced antiproliferative activities via suppressing TGF- $\beta$ and enhancing $p 53$ expression in oral cancer cells. Next, we investigated the possible mechanisms involved in the combined treatments. 
A

B
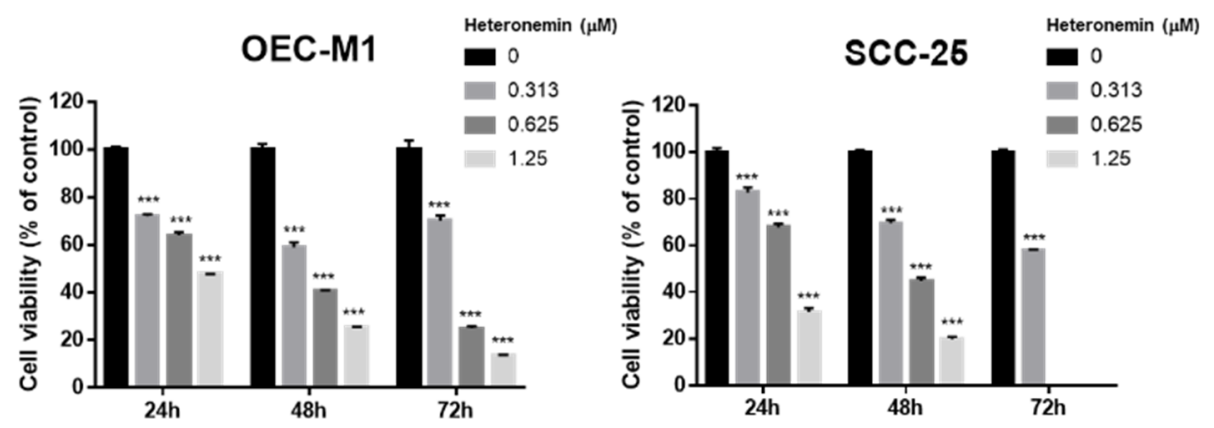

C

Ctrl

Heter. $0.313 \mu \mathrm{M}$
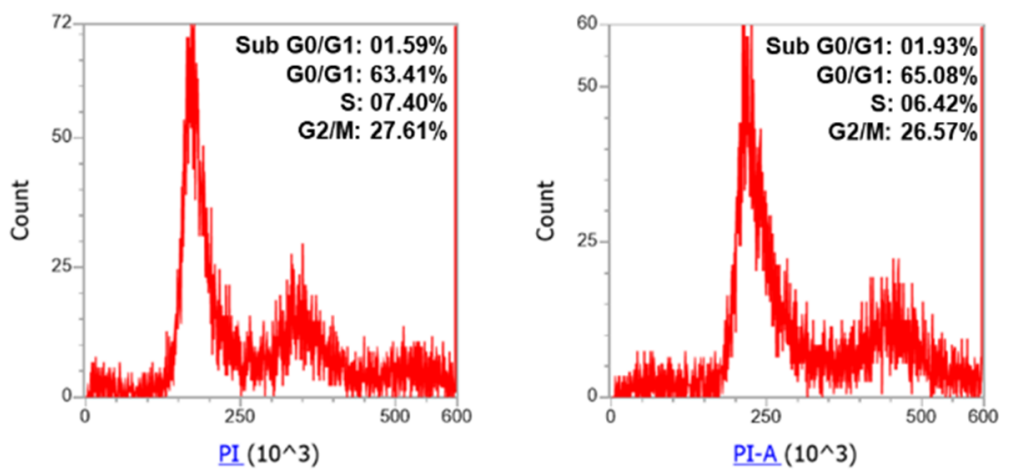

Heter. $0625 \mu \mathrm{M}$

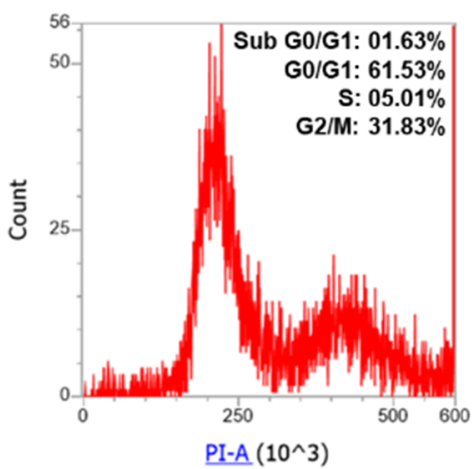

PI-A (10^3)

Heter. $1.25 \mu \mathrm{M}$

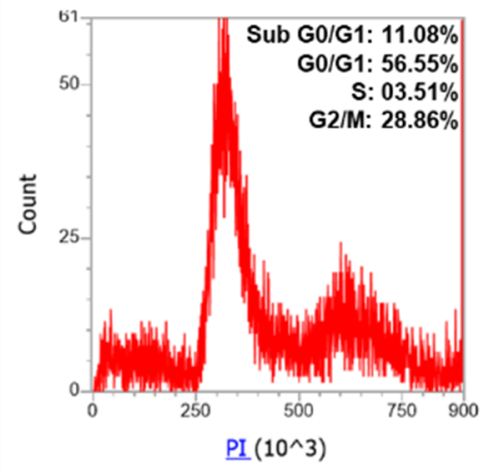

Figure 1. Heteronemin induces antiproliferation and cell cycle analysis in oral cancer cells. OEC-M1 (A) and SCC-25 (B) cells were treated with different concentrations of heteronemin for 24, 48, and $72 \mathrm{~h}$. Cell proliferation was detected with the Cell Counting Kit-8. Number of independent studies $(n)=3$. (C) SCC-25 cells were treated with different concentrations of heteronemin (Heter.) for $24 \mathrm{~h}$. Cell cycle analysis was conducted as described. Cells were harvested, and flow cytometric assay was conducted as described in the Materials and Methods section. $n=3$. Data are expressed as mean \pm SD. ${ }^{* * *} p<0.05$ compared with untreated control. 

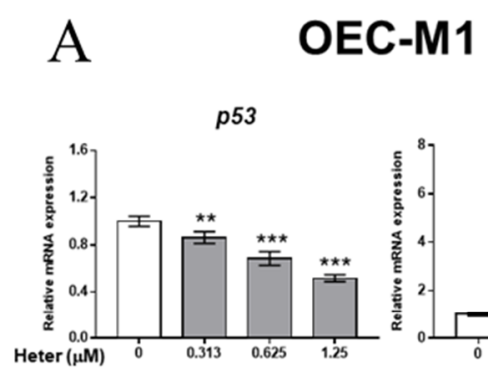

CCND1

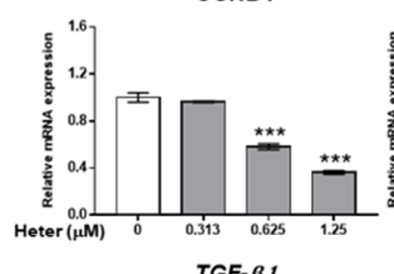

TGF- $\beta 1$

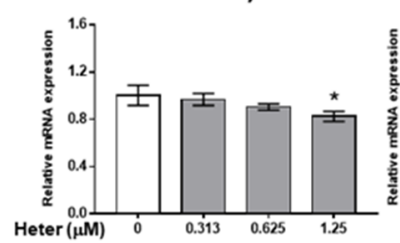

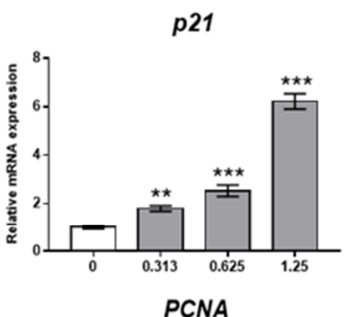

$\mathrm{B}$

\section{SCC-25}
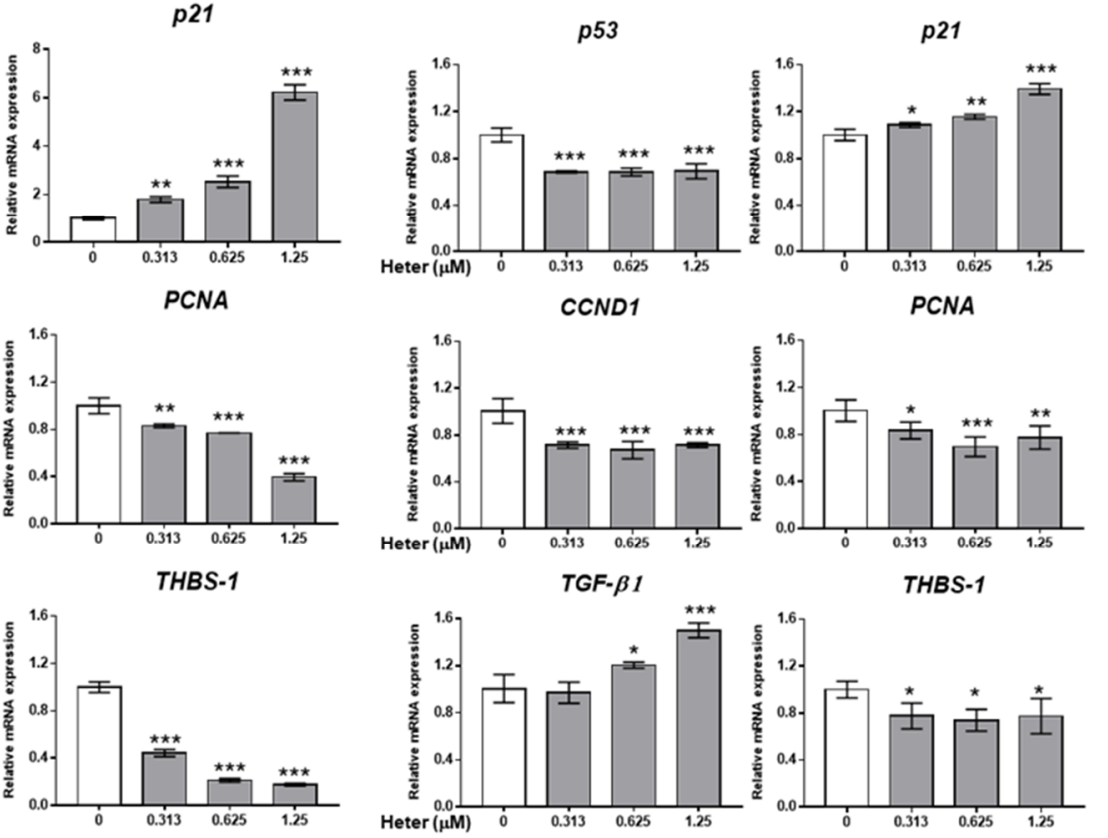

Figure 2. Heteronemin regulates gene expression in oral cancer cells. RNA was extracted from OEC-M1 (A) and SCC-25 (B) cells at the end of treatment for qPCR analyses of $p 53, p 21$, CCND1, PCNA, TGF- $\beta 1$, and THBS-1. Number of independent studies $(n)=3 .{ }^{*} p<0.05,{ }^{* *} p<0.01,{ }^{* * *} p<0.001$, compared to the control for each gene.

\subsection{Tetrac and Heteronemin Inhibit Signal Transduction Pathways in Oral Cancer Cells}

We previously showed that inhibition of STAT3 and ERK1/2 activation plays an important role in antiproliferation in cancer cells $[7,10,15]$. We investigated the mechanisms involved in the heteronemin-induced anti-cancer ability in oral cells. To investigate the signal transduction pathways involved in antiproliferation induced by the combination of tetrac and heteronemin, OEC-M1 and SCC-25 cells were treated with $10^{-7} \mathrm{M}$ tetrac and different concentration of heteronemin, and their combination for $24 \mathrm{~h}$. Then cells were extracted and quantified by RIPA buffer and BCA Protein Assay Kit (Pierce, Rockford, IL, USA), respectively. Western blotting analysis was used to detect the phosphorylation and total protein of STAT3 and ERK1/2 (Figure 3). Tetrac did not affect status of total STAT3 or phosphorylated STAT3 in both cancer cell lines (Figure 3). Heteronemin suppressed phosphorylation of STAT3 activation in OEC-M1 but increased total form starting at $0.625 \mu \mathrm{M}$ (Figure 3 3A, upper panel). The combined treatment showed the highest total STAT3 at $0.313 \mu \mathrm{M}$. Combination treatment with a higher dosage of heteronemin did not further inhibit STAT3 activation. Tetrac $\left(10^{-7} \mathrm{M}\right)$ inhibited ERK1/2 activation significantly in both oral cancer cell lines (Figure 3A,B). Heteronemin inhibited phosphorylation of ERK1/2 activation in a concentration-dependent manner in OEC-M1 cells (Figure 3A, lower panel). The combined treatment at $0.313 \mu \mathrm{M}$ heteronemin with tetrac showed significant decrease as compared with single-agent alone. Parallel studies conducted in SCC-25 cells showed comparable results. Unlike OEC-M1, both phosphorylated STAT3 and total protein of STAT3 were decreased in a dose-dependent manner by heteronemin treatment in SCC-25 (Figure 3B, upper panel). The combined treatment also revealed a decrease in the accumulation of total STAT3. Heteronemin alone significantly reduced phosphorylated ERK1/2, and especially, completely suppressed ERK1/2 activation at $1.25 \mu \mathrm{M}$ (Figure 3B, lower panel). Furthermore, heteronemin combined with tetrac showed the same trend of inhibiting ERK1/2 activation. However, there was no synergistic effect since the inhibitory effect was maximal. These results indicated that both heteronemin and tetrac 
inhibited ERK1/2 activation and heteronemin further blocked STAT3 phosphorylation. The inhibitory effects by heteronemin and tetrac may play important roles in antiproliferation in oral cancer cells.

A OEC-M1 cells

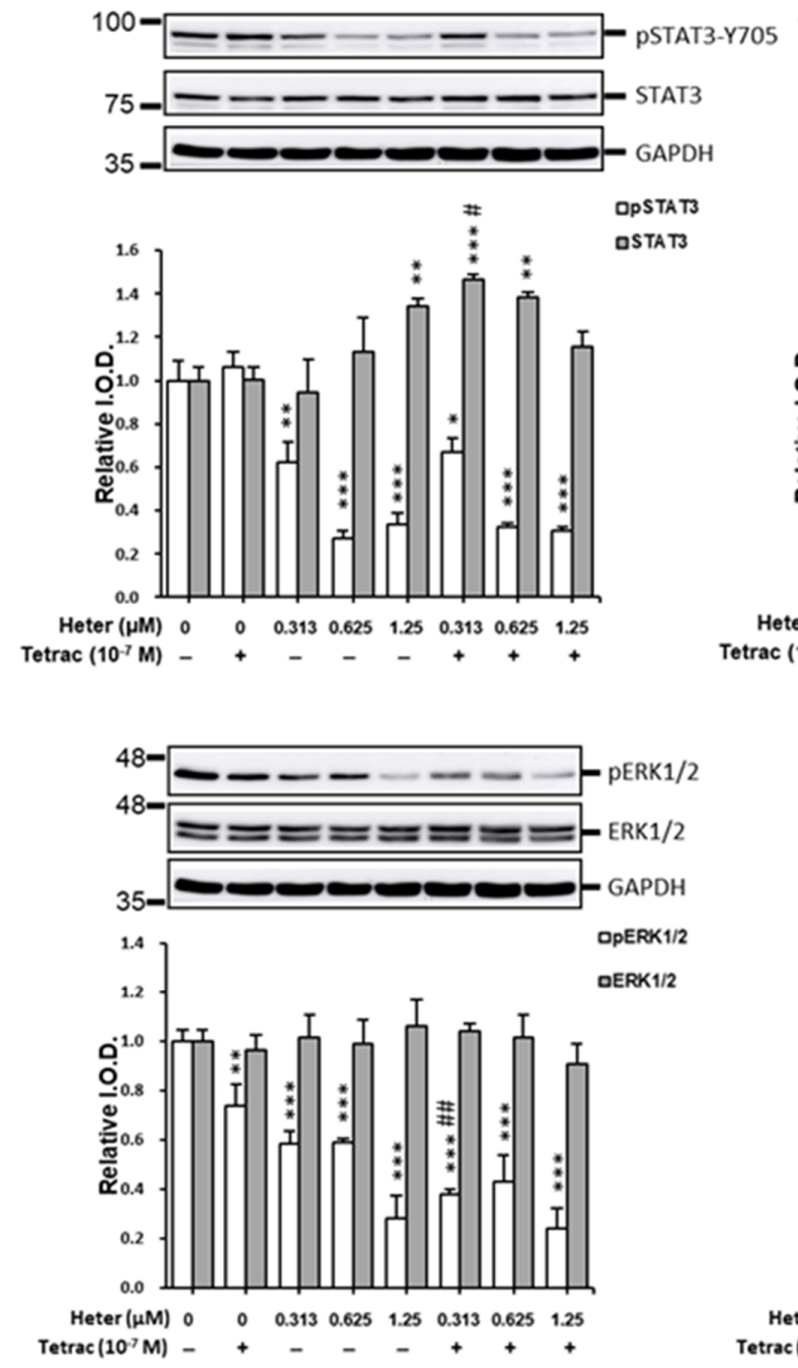

$\mathrm{B}$

\section{SCC-25 cells}
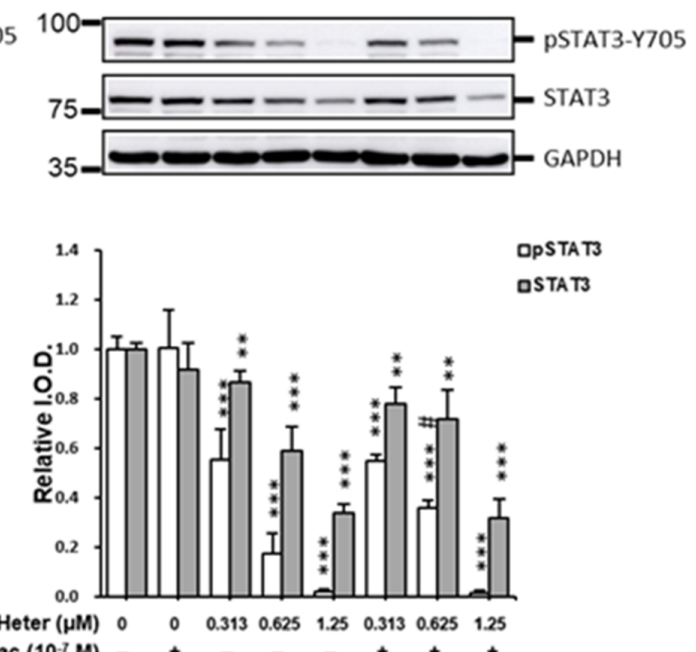

Figure 3. Tetrac and heteronemin inhibit signal transduction pathways in oral cancer cells. OEC-M1 (A) and SCC-25 (B) cells were treated with tetrac, heteronemin, or their combination for $24 \mathrm{~h}$. Cells were harvested, and total proteins were extracted. Western blot analyses were conducted for pSTAT3, STAT3, pERK1/2, and ERK1/2. GAPDH was used as internal control. Number of independent studies $(n)=4 .{ }^{*} p<0.05,{ }^{* *} p<0.01,{ }^{* * *} p<0.001$, compared to the control; ${ }^{\#} p<0.05$, ${ }^{\# \#} p<0.01$ compared to the same dosage of heteronemin treatment only.

We further investigated the effects of combined treatment of $10^{-7} \mathrm{M}$ tetrac and $0.313 \mu \mathrm{M}$ heteronemin on expression of genes involved in cell cycle, proliferation, pro-apoptosis, and angiogenesis. Simultaneous treatment with both heteronemin and tetrac suppressed PCNA and CCND1 expression more significantly than single treatment with tetrac or heteronemin in both OEC-M1 and SCC-25 cells. The expression of $p 21$ was also increased by combination treatment of tetrac and heteronemin, however, the combination treatment did not show further effect on $p 21$ gene expression than heteronemin single treatment (Figure 4). 
OEC-M1

CCND1

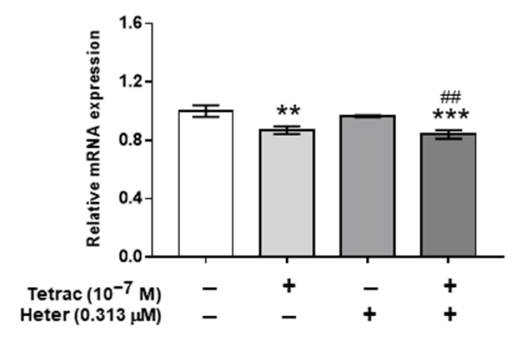

PCNA

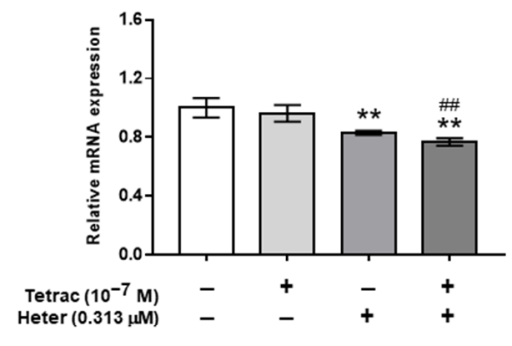

p21

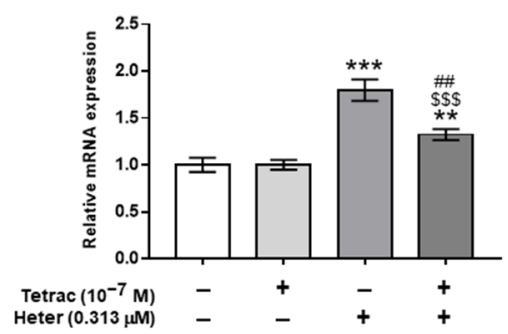

SCC-25

CCND1

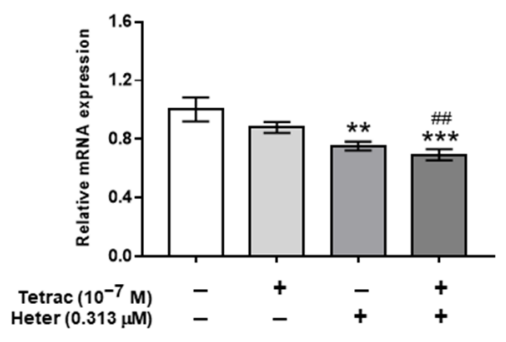

PCNA

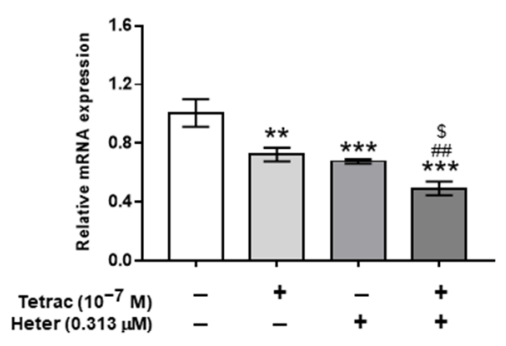

p21

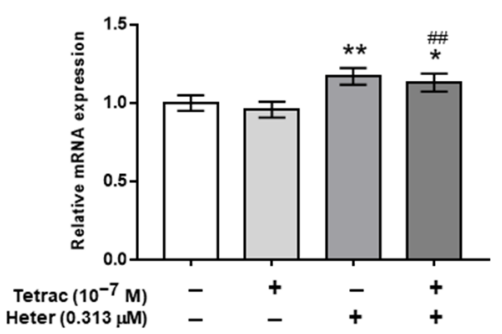

Figure 4. Tetrac and heteronemin regulate cell-cycle-related gene expression in oral cancer cells. OEC-M1 and SCC-25 cells were treated with $0.313 \mu \mathrm{M}$ heteronemin, $10^{-7} \mathrm{M}$ tetrac, or their combination for $24 \mathrm{~h}$. RNA was extracted and qPCR analyses were conducted for CCND1, PCNA, and $p 21$. Numbers of independent studies $(n)=3$. ${ }^{*} p<0.05,{ }^{* *} p<0.01$, ${ }^{* * *} p<0.001$ compared to the control; ${ }^{*} p<0.01$ compared to the tetrac treatment only; ${ }^{\$} p<0.05, \$ \$ p<0.001$ compared to the same dosage of heteronemin treatment only.

Heteronemin did not affect TGF- $\beta 1$ expression significantly, but tetrac treatment and the combination treatment inhibited the expression of TGF- $\beta 1$ in OEC-M1 cells (Figure 5). Both tetrac treatment and the combination treatment inhibited the expression of genes involved in angiogenesis and metastasis, THBS-1 and MMP9. On the other hand, heteronemin alone did not affect expression of THBS-1 and MMP9 in SCC-25 cells. Heteronemin increased expression of TGF- $\beta 1$ in SCC-25 cells but this inductive effect of heteronemin was compensated for in the combination with tetrac treatment (Figure 5). 


\section{OEC-M1}

THBS-1
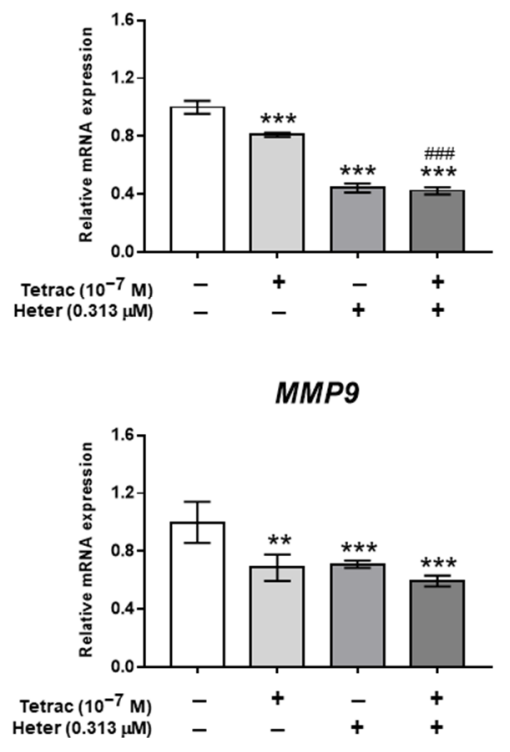

TGF- $\beta 1$

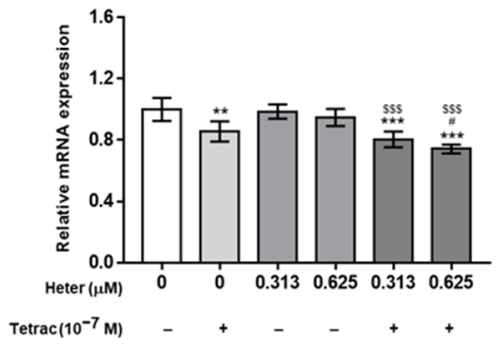

SCC-25

THBS-1
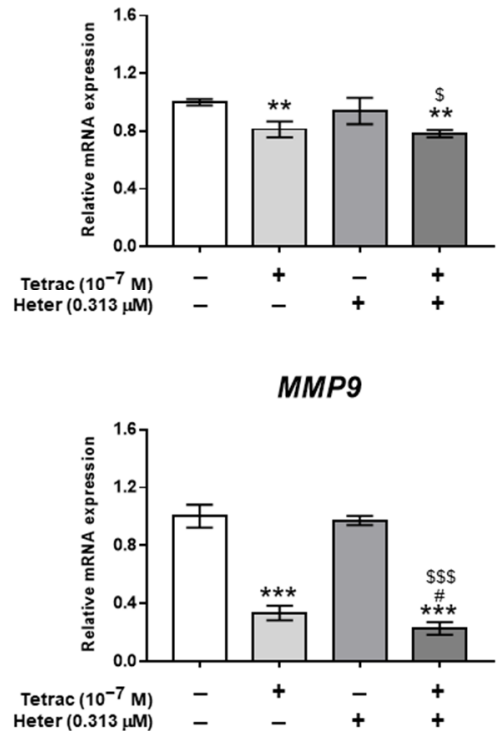

TGF- $\beta 1$

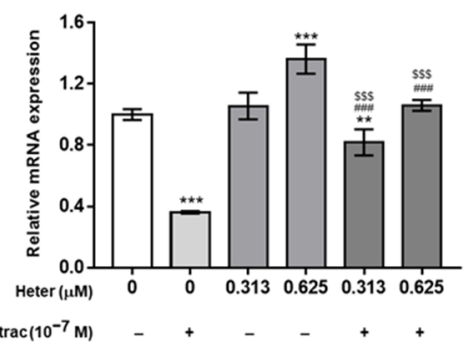

Figure 5. Tetrac and heteronemin regulate gene expression on modulating tumor-stromal function in oral cancer cells. OEC-M1 and SCC-25 cells were treated with 0.313 and $0.625 \mu \mathrm{M}$ heteronemin, $10^{-7} \mathrm{M}$ tetrac, or their combination for $24 \mathrm{~h}$. RNA was extracted from harvested cells at the end of treatment for qPCR studies of THBS-1, MMP9, and TGF- $\beta 1$. Numbers of independent studies $(n)=3 .{ }^{*} p<0.01$, *** $p<0.001$ compared to the control; ${ }^{\#} p<0.05$, \#\#\# $p<0.001$ compared to the tetrac treatment only; $\$ p<0.05, \$ \$ p<0.001$ compared to the same dosage of heteronemin treatment only.

2.3. Tetrac and Heteronemin Synergistically Increase p53 Accumulation and Induce Antiproliferation in Oral Cancer Cells

Since heteronemin inhibited $p 53$ expression in cholangiocarcinoma [2] and in both oral cancer cell lines (Figure 2), we examined if the combined treatment of $10^{-7} \mathrm{M}$ tetrac with different concentrations of heteronemin would change $p 53$ expression. Tetrac increased $p 53$ expression slightly in OEC-M1 cells but significantly in SCC-25 cells (Figure 6A,B, upper panel). However, tetrac did not increase p53 expression in the combination with heteronemin. On the other hand, total p53 protein increased in $0.625 \mu \mathrm{M}$ heteronemin-treated OEC-M1 cells and the combination increased p53 accumulation at concentrations of 0.313 and $0.625 \mu \mathrm{M}$ of heteronemin (Figure 6A, lower panel). Surprisingly, in SCC-25 cells, heteronemin treatment increased p53 accumulation and phosphorylation. Tetrac enhanced p53 accumulation and phosphorylation maximally at $0.625 \mu \mathrm{M}$ heteronemin (Figure $6 \mathrm{~B}$, lower panel). 
A

A

OEC-M1

p53

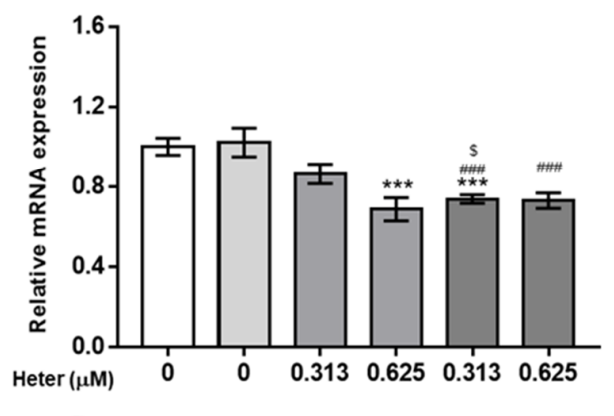

$\operatorname{Tetrac}\left(10^{-7} \mathrm{M}\right) \quad+\quad+\quad+\quad+$
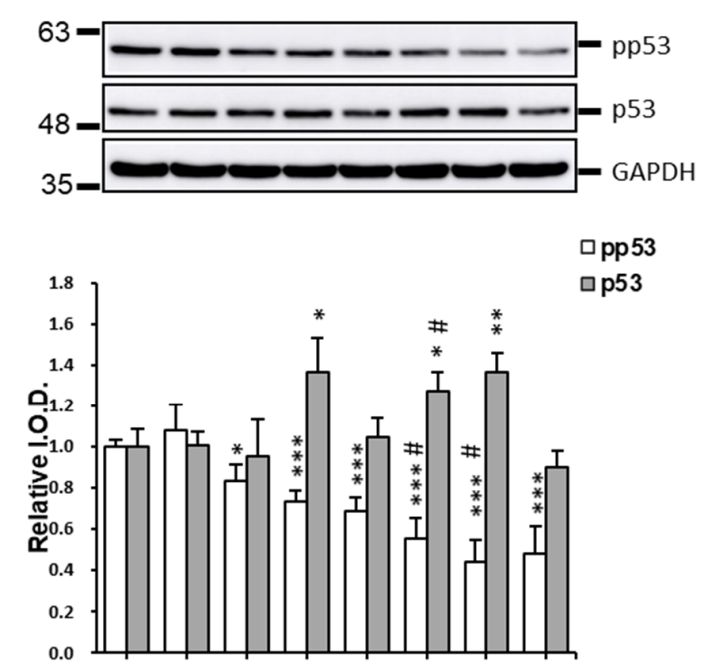

$\begin{array}{lllllllll}\text { Heter }(\mu \mathrm{M}) & 0 & 0 & 0.313 & 0.625 & 1.25 & 0.313 & 0.625 & 1.25\end{array}$
B

SCC-25

p53

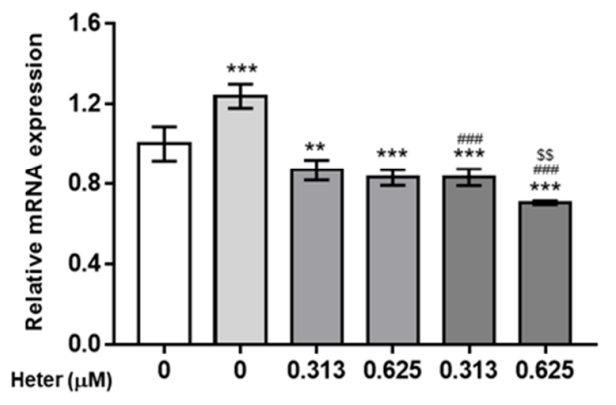

$\operatorname{Tetrac}\left(10^{-7} \mathrm{M}\right) \quad-\quad+\quad+\quad+\quad+$
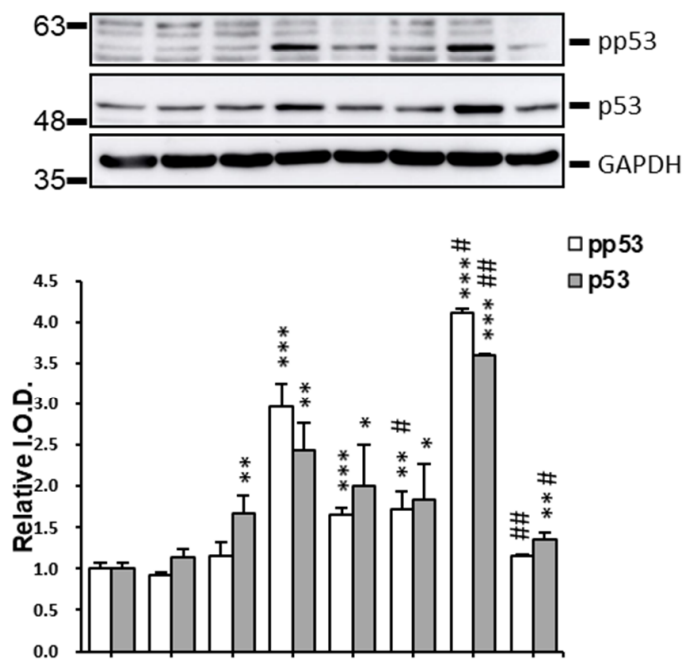

$\begin{array}{lllllllll}\text { Heter }(\mu \mathrm{M}) & 0 & 0 & 0.313 & 0.625 & 1.25 & 0.313 & 0.625 & 1.25\end{array}$ Tetrac $\left(10^{-7} \mathrm{M}\right)$ - + - $~-~+~+~+$

Figure 6. Tetrac and heteronemin regulate $p 53$ expression, p53 accumulation, and phosphorylation in oral cancer cells. OEC-M1 (A) and SCC-25 (B) cells were treated with $10^{-7} \mathrm{M}$ tetrac, different concentrations of heteronemin $(0.313 \mu \mathrm{M}$ to $1.25 \mu \mathrm{M})$, or their combination for $24 \mathrm{~h}$. Cells were harvested and RNA was extracted. qPCR was conducted for $p 53$ (upper panel). $(n)=4$. Western blot analyses were conducted for phpspho-p53 and p53. GAPDH was used as an internal control (lower panel). Number of independent studies $(n)=4$. ${ }^{*} p<0.05$, ${ }^{* *} p<0.01,{ }^{* * *} p<0.001$ compared to the control; ${ }^{\#} p<0.05,{ }^{\# \#} p<0.01,{ }^{\# \#} p<0.001$ compared to the tetrac treatment only; ${ }^{\$} p<0.05,{ }^{\$ \$} p<0.01$ compared to the same dosage of heteronemin treatment only.

We examined the antiproliferative effect of combined treatment of tetrac and heteronemin. OEC-M1 or SCC-25 cells were treated with different concentrations of heteronemin in the presence or absence of tetrac $\left(10^{-7} \mathrm{M}\right)$ for $48 \mathrm{~h}$. Although tetrac did not inhibit the cell growth of OEC-M1, the combined treatment with heteronemin $(0.313 \mu \mathrm{M}$ and $0.625 \mu \mathrm{M})$ and tetrac had a synergetic effect on antiproliferation in OEC-M1 cells (Figure 7A). Similar results were observed in SCC-25 cells (Figure 7B). 
A

\section{OEC-M1}

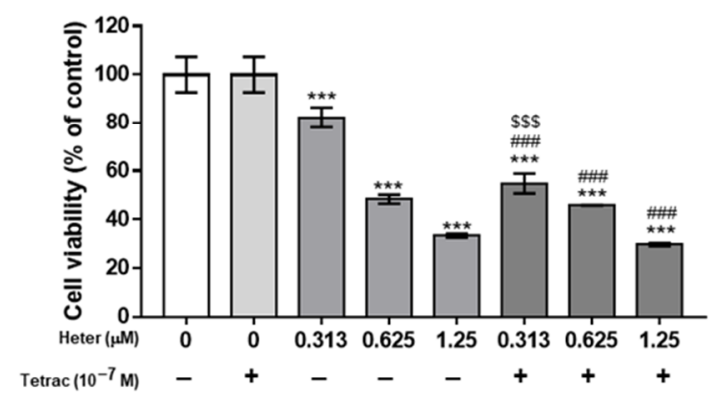

$\mathrm{B}$

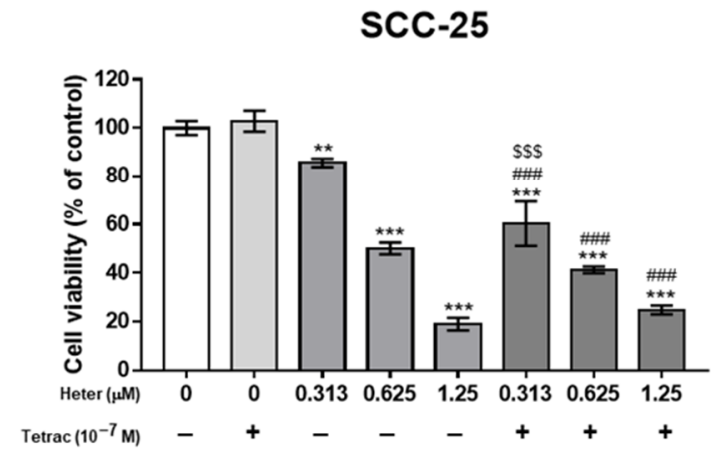

Figure 7. Combined treatment with heteronemin and tetrac suppressed proliferation in oral cancer cells. OEC-M1 (A) and SCC-25 (B) cells were treated with tetrac and different concentrations of heteronemin for $48 \mathrm{~h}$. Cell proliferation was detected with a Cell Counting Kit-8. Number of independent studies $(n)=3{ }^{* *} p<0.01,{ }^{* * *} p<0.001$, compared to the control; ${ }^{\# \# \#} p<0.001$, compared to the tetrac treatment only; $\$ \$ p<0.001$ compared to the same dosage of heteronemin treatment only.

To understand whether tetrac or heteronemin has a direct functional role in the regulation of cell cycle and apoptosis in oral cancer cells, we performed propidium iodide (PI) staining for further exploration. The percentage of each cell phase stage in OEC-M1 and SCC-25 are shown in Figure 8. The percentages of cell stages in OEC-M1 and SCC- 25 cells showed a different trend. The percentage G0/G1 in OEC-M1 was increased with heteronemin but did not increase in the combination group (Figure 8A). However, the sub-G0/G1 phase of OEC-M1 cells in the combined treatment was higher than with heteronemin alone $(0.625 \mu \mathrm{M})$. Thus the results indicated that the levels of apoptotic and dead cells were increased by heteronemin combined with tetrac. Then again, the acute cell death of OEC-M1 induced by high concentration of heteronemin might have been due to drug susceptibility (data not shown). The cell phase of SCC-25 tended to G2/M after heteronemin treatment (Figure 8B). Moreover, a similar phenomenon was observed in the combined heteronemin and tetrac treatment. Interestingly, there was a ten percent raise in sub-G0/G1 phase in $1.25 \mu \mathrm{M}$ heteronemin-treated SCC-25 cells compared with the untreated control, but $2 \%$ of sub-G0/G1 was rescued when tetrac was present (data not shown). Therefore, in the heteronemin and combined treatment groups, OEC-M1 and SCC-25 showed G0/G1 and G2/M arrest, respectively. Additionally, both of them increased the value of sub-G0/G1 phase at 0.313 and $0.625 \mu \mathrm{M}$ conditions. Our results revealed the drug-dependent induction of apoptosis in the combination treatment. 
A

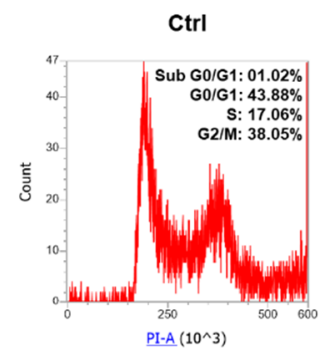

Heter. $0.313 \mu \mathrm{M}$

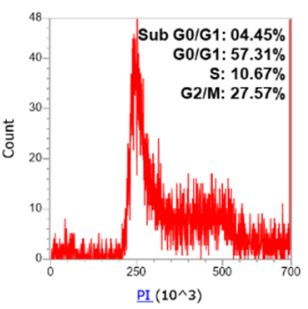

Heter. $\mathbf{0 . 6 2 5} \mu \mathbf{M}$

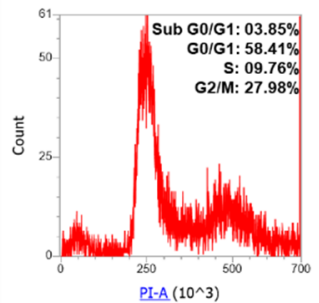

OEC-M1

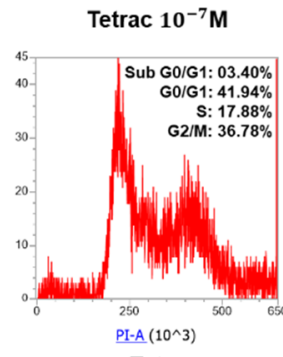

Tetrac+ Heter. $0.313 \mu \mathrm{M}$

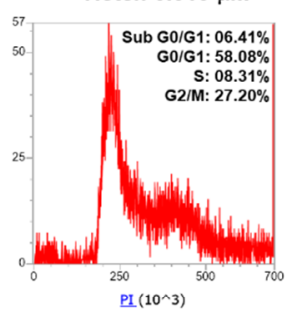

Tetract

Heter. $0.625 \mu \mathrm{M}$

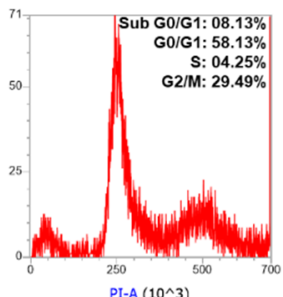

B

\section{SCC-25}
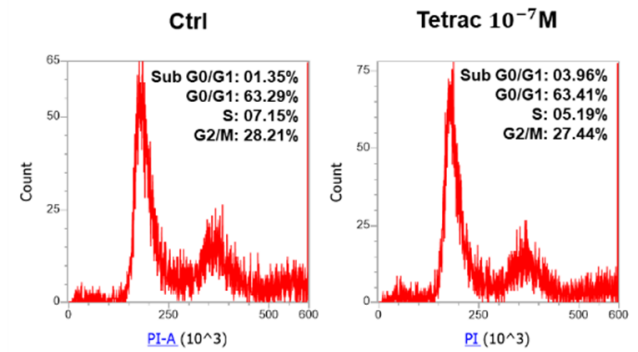

Tetrac+

Heter. $0.313 \mu \mathrm{M}$

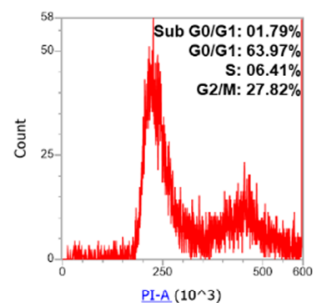

Heter. $\mathbf{0 . 3 1 3} \mu \mathrm{M}$

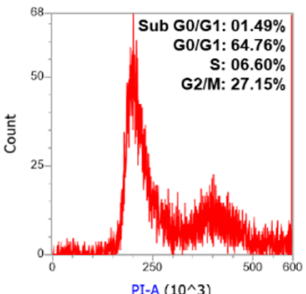

Heter. $0.625 \mu \mathrm{M}$

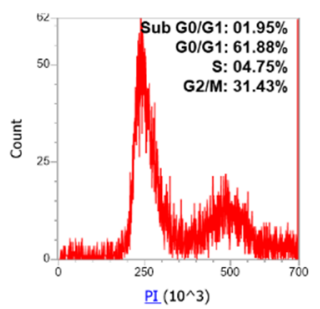

Tetract

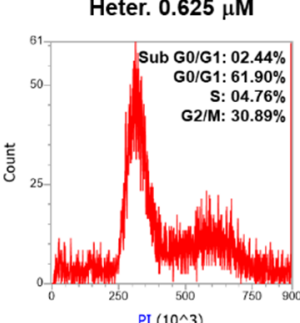

Figure 8. Combined treatment with heteronemin and tetrac induced cell cycle arrest in oral cancer cells. OEC-M1 (A) and SCC-25 (B) cells were treated with different concentrations of heteronemin in the presence or absence of $10^{-7} \mathrm{M}$ tetrac for $24 \mathrm{~h}$. Cells were harvested, and flow cytometric assay was conducted as described in the Materials and Methods section. $(n)=3$.

\section{Discussion}

A deaminated analog of thyroxine $\left(\mathrm{T}_{4}\right)$, tetrac, and NDAT can inhibit cancer proliferation via the receptor of the cell surface integrin, $\alpha v \beta 3$. Tetrac and NDAT reduce expression of pro-inflammatory genes, such as interleukin (IL)-1 $\alpha, I L-1 \beta$, and IL-6 [16]. They increase expression of IL-11, a desirable stimulator of hematopoietic stem cell proliferation [16]. Additionally, NDAT downregulates expression of the apoptosis inhibitors, X-linked inhibitor of apoptosis (XIAP) and myeloid cell leukemia sequence 1 (MCL1) and upregulates apoptosis-promoting CASP2 and BCL2L14. Tetrac and NDAT increase THBS-1 and CBY1, a nuclear inhibitor of $\beta$-catenin activity in various types of cancer cells $[17,18]$. Both tetrac and NDAT were shown to downregulate expression of K-Ras and EGFR. Additionally, they potentiate other anticancer agents such as cetuximab- [11] or gefitinib-induced [12] anticancer activities. They are also used to compensate natural products such as resveratrol-induced anti-cancer treatment in colorectal cancers in in vitro and in vivo xenograft models [3,7]. Additionally, NDAT was shown to enhance resveratrol-induced antiproliferation in oral cancer cells [15]. In current studies, tetrac was able to inhibit expression of CCND1, PCNA, and THBS-1 in both OEC-M1 and SCC-25 cells (Figure 4). THBS-1 has been shown to play a tumorigenic role in oral cancers [19].

Tetrac inhibits ERK1/2 activation to inhibit cancer proliferation that has been well-established [10]. Heteronemin is an inhibitor of STAT3 [6]. Heteronemin inhibited not only STAT3 but also ERK1/2 activation in both OEC-M1 cells and SCC- 25 cells (Figure 3). Tetrac inhibited ERK1/2 but not STAT3 activation in OEC-M1 cells and SCC-25 cells (Figure 3). These results suggest that heteronemin and 
tetrac may induce antiproliferation via a different signal transduction pathway. This phenomenon was observed in our previous studies. Resveratrol induces antiproliferation via ERK1/2 activation [20] while tetrac inhibits cell proliferation via ERK1/2 inhibition. Tetrac potentiates resveratrol-induced antiproliferation without affecting resveratrol-induced ERK1/2 activation [3]. Studies conducted by Ho Y., et al. also indicate that resveratrol induced ERK1/2 activation and NDAT inhibited ERK1/2 activation, but their combination induced antiproliferation of oral cancer cells [15].

Heteronemin inhibited proliferation (Figure 1) and proliferative gene expression (Figure 2) in both oral cancer cells. It also inhibited expression of PCNA, CCND1, and THBS-1. Pro-apoptotic p21 expression was enhanced by heteronemin in a concentration-dependent manner. Interestingly, heteronemin at $0.313 \mu \mathrm{M}$ significantly suppressed expression of THBS-1 and $p 53$ (Figure 2). Heteronemin and tetrac both inhibited THBS-1 expression (Figures 2, 4 and 5). Tetrac was shown to stimulate THBS-1 expression in other types of cancer cells such as breast cancer [21], medullary carcinoma of the thyroid [22], and pancreatic cancer [23]. However, expression of THBS-1 was demonstrated to be induced by TGF- $\beta 1$ in cancer stroma and to promote invasion of oral squamous cell carcinoma [19]. The combined treatment of tetrac and heteronemin more strongly reduced TGF- $\beta 1$ expression (Figure 5).

Both tetrac and heteronemin inhibited TGF- $\beta 1$ expression (Figure 5). Knocking-down TGF- $\beta 1$ enhanced heteronemin-induced antiproliferation [24]. These results indicate that co-treatment with tetrac and heteronemin induced antiproliferation via TGF- $\beta$ suppression. TGF- $\beta$ acts as a tumor promoter in the progressive stages of cancers to support tumor cell proliferation, invasion, metastasis, and immune evasion [25-29]. TGF- $\beta$ forms a heterotetrameric complex with TGF- $\beta$ R1 thereby initiating binding with the TGF- $\beta$ receptor II (TGF- $\beta$ RII). Successively, TGF- $\beta$ R1 is phosphorylated by TGF- $\beta$ RII to recruit and phosphorylate the cytosolic transcription factors, SMAD2 and SMAD3 [30-32]. Phosphorylated SMAD2/3 forms a complex with co-SMAD (SMAD4) after dissociation from TGF- $\beta$ Rs. The formed transcriptional complex is translocated into the nucleus and regulates expression of numerous target genes [33,34].

Additionally, TGF- $\beta$ signaling also activates several non-SMAD pathways, for example PI3K/AKT, INK/p38, Ras-ERK, and RhoA pathways [25,34]. Heteronemin inhibited both pERK1/2 activation and STAT3 phosphorylation (Figure 3). Moreover, heteronemin promoted TGF- $\beta 1$ expression in OEC-M1 cells (Figure 5) which may have also reduced TGF- $\beta 1$-induced activation of ERK1/2 and STAT3. Although heteronemin did not inhibit TGF- $\beta 1$ expression in SCC-25 cells, tetrac also inhibited TGF- $\beta 1$ expression which may compensate the TGF- $\beta 1$ expression effect of heteronemin in SCC-25 cells.

Interestingly, TGF- $\beta$ was shown to possess antitumor activity [35]. The crosstalk between p53 signaling and TGF- $\beta$ is well documented [36]. The antitumor effect of TGF- $\beta$ signaling stabilizes the accumulation and recruitment of wild-type p53 to its DNA-binding sites. Inactivation of p53 interrupts TGF- $\beta$-induced cellular activities. However, crosstalk between p53 and TGF- $\beta$ signaling demonstrates that p53 can act as a component of SMAD complexes that participates in the stabilization of SMAD-DNA complexes and modulates various tumor suppressor genes [37-41]. In addition, heteronemin reduced $p 53$ expression (Figure 2). Knockdown of p53 did not reduce or affect the abundance of TGF- $\beta$ [2], indicating that p53 might not be associated with TGF- $\beta$ forming a complex with, and stabilizing p53 in oral cancers. Heteronemin reduced expression of both TGF- $\beta 1$ and $p 53$ in oral cancer cells (Figure 2) and cholangiocarcinomas [2]. Together, the results suggest that heteronemin suppressed oncogenic TGF- $\beta 1$ expression to induce antiproliferation in which p53 does not play a role in oral cancer cells.

Tetrac did not affect $p 53$ expression, but heteronemin inhibited p53 expression in OEC-M1 cells and SCC-25 cells (Figure 6). Combined treatment with tetrac and heteronemin even downregulated p53 expression (Figure 6). However, tetrac, $0.625 \mu \mathrm{M}$ heteronemin, or the combination increased total p53 amount in OEC-M1 cells. Tetrac, heteronemin, or the combination increased not only total p53 amount but also phosphorylated p53 in SCC-25 cells. These results suggest that combined tetrac and heteronemin may stabilize p53 or increase its phosphorylation. 
There were different trends of cell cycles between OE-CM1 and SSC-25 treated with heteronemin and tetrac (Figure 8). These two drugs had been shown to inhibit cancer cell growth in the previous studies. Our results further confirmed the population of sub-G0/G1 in oral cancer cells was increased by tetrac or heteronemin treatment alone. Heteronemin and tetrac showed a significantly synergistic growth-inhibitory effect on OEC-M1 and SCC-25 cells under the combined treatment group of $0.625 \mu \mathrm{M}$ heteronemin. The phenomena of cell cycle are consistent with our experiments in cell proliferation (Figure 7). Although high concentration of heteronemin $(1.25 \mu \mathrm{M})$ caused more cell death in these cells, the sub-G0/G1 and G0/G1 of SCC-25 could be rescued by tetrac. For heteronemin or combined treatment, increasing cell cycle arrest of G0/G1 and G2/M was observed in OEC-M1 and SCC-25, respectively. Thus OEC-M1 and SCC-25 showed different trends in populations of cell cycle. We suggested that the difference is caused by a resistant gene or p53 mutation in SCC-25 cells after drug treatment.

Compared with the cell cycle of OEC-M1, it suggested that the p53 mutation of SCC-25 may be one of the reasons for the different trends between them. Based on RT-PCR data and Western blot analysis, the differential expression of p21, p53, and CCND1 in oral cancer cells after heteronemin or tetrac treatment may play critical roles in the G0/G1 cell cycle arrest that blocks cell proliferation and induces apoptosis.

\section{Materials and Methods}

\subsection{Cell Culture}

An indigenous human oral epidermoid carcinoma OEC-M1 cell was established from a gingival epidermal carcinoma of a patient in Taiwan by Dr. Ching-Liang Meng [42]. This cell line was a gift from Dr. Hsien-Chung Chiu. Human squamous carcinoma of the tongue SCC-25 cells (ATCC ${ }^{\circledR}$ CRL-1628 ${ }^{\mathrm{TM}}$ ) were obtained from the American Type Culture Collection (ATCC; Manassas, VA, USA). Cells were tested and authenticated with Bioresource Collection and Research Center of Taiwan (through an isoenzyme analysis, mycoplasma, cytogenetics, tumorigenesis, and receptor expression testing). OEC-M1 and SCC-25 cells were respectively maintained in RPMI-1640 and Dulbecco's modified Eagle medium (DMEM)/F12 supplemented with $10 \%$ fetal bovine serum (FBS) at $37{ }^{\circ} \mathrm{C}$ in a humidified incubator with $5 \% \mathrm{CO}_{2}$ and $95 \%$ air. Cells at no later than passage 15 were used for the experiments. Before the treatment, cells were placed in serum-free medium for $24 \mathrm{~h}$. In treatment condition, cells were incubated in respective medium with $2 \%$ FBS.

\subsection{Flow Cytometric Analysis}

Oral cancer cells were grown in 100-mm tissue culture dishes until $80 \%$ confluent and treated daily with different reagents for $24 \mathrm{~h}$ with refreshed medium containing reagents. Cells were harvested by trypsinization, washed with phosphate-buffered saline (PBS) and re-suspended in $200 \mu \mathrm{L}$ PBS $\left(10^{5}\right.$ to $10^{6}$ cells). To quantify cellular DNA contents, cells were permeabilized by fixation with $70 \%$ ethanol for $30 \mathrm{~min}$ at $4{ }^{\circ} \mathrm{C}$. Samples were stored in $70 \%$ ethanol at $-20^{\circ} \mathrm{C}$ for up to two weeks prior to propidium iodide (PI) staining and the flow cytometric analysis. $1 \mathrm{~mL} 0.5 \%$ triton buffer containing RNase A $(0.05 \%)$ was added to the cell suspension, and incubation was carried out at $37^{\circ} \mathrm{C}$ for $1 \mathrm{~h}$; cells were then stained PI $(50 \mu \mathrm{g} / \mathrm{mL})$ and maintained in the dark at room temperature for $30 \mathrm{~min}$. Flow cytometry was carried out on an Invitrogen Attune ${ }^{\mathrm{TM}}$ NxT Acoustic Focusing Cytometer (ThermoFisher Scientific, Waltham, MA, USA) instrument. The percentages of DNA content were analyzed using Attune NxT Flow Cytometer software (version 4.2) to determine the fractions in each phase of cell cycle (G0/G1, S, and $\mathrm{G} 2 / \mathrm{M})$.

\subsection{Cell Proliferation Assay}

Cell proliferation was evaluated using the Cell Counting Kit-8 (cat. no.: 96992, Sigma-Aldrich, St. Louis, MO, USA). The assay was performed in 96-well microplates with phenol red medium (RPMI-1640: OEC-M1; DMEM/F12: SCC-25). Cells were seeded into 96-well plates at a density of 
$1.5 \times 10^{3}$ cells/well and cultured in $5 \% \mathrm{CO}_{2}$ at $37^{\circ} \mathrm{C}$ overnight. On the second day, the medium was replaced with fresh medium without FBS, and then incubated for $24 \mathrm{~h}$ at $37^{\circ} \mathrm{C}$. 'Various concentrations of tetrac and heteronemin were added, and six wells were arranged in one column for each condition. Media with or without the drug were refreshed every 2 days. For the detection step, the CCK- 8 reagent $(10 \mu \mathrm{L})$ was added to each well after 2 days of drug treatment and incubated for $1 \mathrm{~h}$ at $37^{\circ} \mathrm{C}$. The optical absorbance was read with a VersaMax Microplate reader (Molecular Device, San Jose, CA, USA) at a wavelength of $450 \mathrm{~nm}$. The readings were normalized to blank medium. Cell proliferation was calculated as the ratio of the readings of the treatment group to the control group.

\subsection{Real-Time Quantitative Polymerase Chain Reaction ( $q P C R$ )}

Total RNA was extracted and genomic DNA was removed with an Illustra RNAspin Mini RNA Isolation Kit (GE Healthcare Life Sciences, Buckinghamshire, UK). One microgram of DNase I-treated total RNA was reverse-transcribed with a RevertAid H Minus First Strand cDNA Synthesis Kit (Thermo Fisher Scientific) into complementary (c)DNA and used as the template for the real-time PCRs and analysis. The real-time PCRs were performed using a QuantiNovaTM SYBR ${ }^{\circledR}$ Green PCR Kit (Qiagen, Hilden, Germany) on a CFX Connect ${ }^{\mathrm{TM}}$ Real-Time PCR Detection System (Bio-Rad Laboratories, Hercules, CA, USA). This involved initial denaturation at $95{ }^{\circ} \mathrm{C}$ for $5 \mathrm{~min}$, followed by 40 cycles of denaturing at $95{ }^{\circ} \mathrm{C}$ for $5 \mathrm{~s}$ and combined annealing/extension at $60{ }^{\circ} \mathrm{C}$ for $10 \mathrm{~s}$, as detailed in the manufacturer's instructions. The primer sequences were shown as follows: Homo sapiens cyclin D1 (CCND1), forward 5'-CAAGGCCTGAACCTGAGGAG-3' and reverse 5'-GATCACTCTGGAGAGGAAGCG-3' (Accession no.: NM_053056); Homo sapiens proliferating cell nuclear antigen (PCNA), forward 5'-TCTGAGGGCTTCGACACCTA-3' and reverse 5'-TCATTGCCGGCGCATTTTAG-3' (Accession No.: BC062439.1); Homo sapiens cyclin-dependent kinase inhibitor 1A (p21), forward 5'-CTGGGGATGTCCGTCAGAAC-3' and reverse 5'-CATTAGCGCATCACAGTCGC-3' (accession no.: BT006719.1); Homo sapiens tumor protein p53 (p53), forward 5'-AAGTCTAGAGCCACCGTCCA-3' and reverse 5'-CAGTCTGGCTGCCAATCCA-3' (Accession No.: NM_000546.5); Homo sapiens transforming growth factor (TGF- $\beta$ ), forward 5'-GCCCTGGACACCAACTATTGC-3' and reverse 5'-GCTGCACTTGCAGGAGCGCAC-3' (accession no.: NM_000660.6); Homo sapiens thrombospondin 1 (THBS-1) forward 5'- ATCCTGGACTCGCTGTAGGT-3' and reverse 5'GTCATCGTCCCTTTCGGTGT-3' (Accession no.: NM_003246.6); Homo sapiens matrix metallopeptidase 9 (MMP-9), forward 5' TGTACCGCTATGGTTACACTCG 3' and reverse 5' GGCAGGGACAGTTGCTTCT 3' (Accession no.: NM_004994.3); Homo sapiens Catenin beta-1 ( $\beta$-catenin) forward 5'CTGGTCCTTTTTGGTCGAGGA-3' and reverse 5'- GCAAGGCTAGGGTTTGATAAAT-3' (Accession no.: NM_001904.4); and Homo sapiens Caspase 2 (CASP2) forward 5'-GCATGTACTCCCACCGTTGA-3' and reverse 5'-GACAGGCGGAGCTTCTTGTA-3' (Accession no.: NM_032982.4). Calculations of the relative gene expression (normalized to $18 \mathrm{~S}$ reference gene) were performed according to the $\Delta \Delta \mathrm{CT}$ method. Fidelity of the PCR was determined with a melting temperature analysis.

\subsection{Western Blotting}

Western blot analyses were conducted as previously described $[43,44]$. In brief, after treatment with tetrac, heteronemin, or their combination, cells were harvested. Total proteins were extracted and quantified. Protein samples were resolved by $10 \%$ sodium dodecylsulfate-polyacrylamide gel electrophoresis (SDS-PAGE). A 30- $\mu$ g quantity of protein was loaded in each well with $5 \times$ sample buffer, and samples were resolved with electrophoresis at $100 \mathrm{~V}$ for $2 \mathrm{~h}$. The resolved proteins were transferred from the polyacrylamide gel to Millipore Immobilon-PSQ Transfer polyvinylidene difluoride (PVDF) membranes (Millipore, Billerica, MA, USA) with Mini Trans-Blot ${ }^{\circledR}$ Cell (Bio-Rad Laboratories). Membranes were blocked with a solution of 5\% skim milk in Tris-buffered saline. Membranes were incubated with primary antibodies to phosphorylated (phospho)-ERK, phospho-STAT3, and their corresponding proteins (Cell Signaling Technology, Beverly, MA, USA), and GAPDH (GeneTex 
International, Hsinchu City, Taiwan) overnight at $4{ }^{\circ} \mathrm{C}$. Proteins were detected with horseradish peroxidase (HRP)-conjugated secondary antibodies and Immobilon ${ }^{\mathrm{TM}}$ Western HRP Substrate Luminol Reagent (Millipore, Burlington, MA USA). Western blots were visualized and recorded with the Amersham Imager 600 system (GE Healthcare Life Sciences, Pittsburgh, PA, USA). The densitometric analysis of Western blots was conducted with Image J 1.47 software (National Institute of Health, Bethesda, MD, USA) according to the software's instructions.

\subsection{Quantification of Results and Statistical Analysis}

Densities of Western blots and gene expressions of the real-time qPCR were analyzed by IBM SPSS Statistics software version 19.0 (SPSS, Chicago, IL, USA). Student's t-test was conducted, and changes were considered significant at $p<0.05(*, \#, \$), 0.01(* *, \# \#, \$$ ) and $0.001(* * *, \# \#, \$ \$$ ).

\section{Conclusions}

In conclusion, heteronemin induced antiproliferation in oral cancer cells by inhibiting activation of ERK1/2 and STAT3. Heteronemin suppressed expression of $p 53$ and THBS-1. In addition, heteronemin inhibited TGF- $\beta 1$ expression in OEC-M1 cells but activated TGF- $\beta 1$ expression in SCC-25 cells. On the other hand, tetrac did not suppress p53 expression but inhibited THBS-1 expression in both oral cancer cell lines. Additionally, tetrac suppressed TGF- $\beta$ expression in combination with heteronemin which may have compensated for heteronemin-induced suppression of $p 53$. The different trend of cell population in OEC-M1 and SCC-25 may have been due to p53 mutation, whereas the sub-G0/G1 in two cells was increased after combined treatment. Therefore, combined treatment with heteronemin and tetrac is able to enhance heteronemin-induced antiproliferation in oral cancer cells.

Author Contributions: Conceptualization: H.-M.H. and S.-Y.L.; Methodology: C.-H.H., T.-Y.H., Y.-T.C., and C.-N.H.; Formal analysis: W.-J.C. and H.-R.C.; Investigation: T.-Y.H., H.-R.C., Y.-S.P., Z.-L.L., S.U., Y.-T.C., and C.-Y.L.; Writing—original draft preparation: H.-Y.L., T.-Y.H., and H.-M.H.; Writing—review and editing: F.G., P.D.V., J.Z.P., S.I., S.U., P.J.D., and Y.-R.C.; Visualization: H.-R.C. and Z.-L.L.; Project administration: H.-Y.L., K.W. and J.W.-P.; Funding acquisition: H.-Y.L., S.-Y.L., and J.W.-P.; All authors have read and agreed to the published version of the manuscript.

Funding: This research was funded in part by a Research Award from the Ta-Cheng Tung Foundation and by the Chair Professor Research Fund to Kuan Wang and to Jacqueline Wang-Peng, and the TMU Research Center of Cancer Translational Medicine from The Featured Areas Research Center Program within the framework of the Higher Education Sprout Project, by the Ministry of Education (MOE) in Taiwan (DP2-107-20000), and by grants from the Ministry of Science and Technology, Taiwan (MOST 108-2314-B-038-033-MY2 to Sheng-Yang Lee; MOST108-2314-B-038-050 to H.Y. Lin; and MOST108-2119-038-001 to Jacqueline Wang-Peng).

Conflicts of Interest: The authors declare no conflict of interest.

\section{References}

1. Tseng, C.H. Oral cancer in Taiwan: Is diabetes a risk factor? Clin. Oral Investig. 2013, 17, $1357-1364$. [CrossRef] [PubMed]

2. Lin, H.Y.; Tey, S.L.; Ho, Y.; Chin, Y.T.; Wang, K.; Whang-Peng, J.; Shih, Y.J.; Chen, Y.R.; Yang, Y.N.; Chen, Y.C.; et al. Heteronemin induces anti-proliferation in cholangiocarcinoma cells via inhibiting tgf-beta pathway. Mar. Drugs 2018, 16, 489. [CrossRef]

3. Nana, A.W.; Chin, Y.T.; Lin, C.Y.; Ho, Y.; Bennett, J.A.; Shih, Y.J.; Chen, Y.R.; Changou, C.A.; Pedersen, J.Z.; Incerpi, S.; et al. Tetrac downregulates beta-catenin and hmga2 to promote the effect of resveratrol in colon cancer. Endocr. Relat. Cancer 2018, 25, 279-293. [CrossRef] [PubMed]

4. Huang, H.H.; Kuo, S.M.; Wu, Y.J.; Su, J.H. Improvement and enhancement of antibladder carcinoma cell effects of heteronemin by the nanosized hyaluronan aggregation. Int. J. Nanomed. 2016, 11, 1237-1251. [CrossRef] [PubMed] 
5. Cheng, M.H.; Huang, H.L.; Lin, Y.Y.; Tsui, K.H.; Chen, P.C.; Cheng, S.Y.; Chong, I.W.; Sung, P.J.; Tai, M.H.; Wen, Z.H.; et al. Ba6 induces apoptosis via stimulation of reactive oxygen species and inhibition of oxidative phosphorylation in human lung cancer cells. Oxid. Med. Cell Longev. 2019, 2019, 6342104. [CrossRef]

6. Wu, J.C.; Wang, C.T.; Hung, H.C.; Wu, W.J.; Wu, D.C.; Chang, M.C.; Sung, P.J.; Chou, Y.W.; Wen, Z.H.; Tai, M.H. Heteronemin is a novel c-met/stat3 inhibitor against advanced prostate cancer cells. Prostate 2016, 76, 1469-1483. [CrossRef]

7. Nana, A.W.; Wu, S.Y.; Yang, Y.S.; Chin, Y.T.; Cheng, T.M.; Ho, Y.; Li, W.S.; Liao, Y.M.; Chen, Y.R.; Shih, Y.J.; et al. Nano-diamino-tetrac (ndat) enhances resveratrol-induced antiproliferation by action on the rrm2 pathway in colorectal cancers. Horm. Cancer 2018, 9, 349-360. [CrossRef] [PubMed]

8. Latteyer, S.; Christoph, S.; Theurer, S.; Hones, G.S.; Schmid, K.W.; Fuehrer, D.; Moeller, L.C. Thyroxine promotes lung cancer growth in an orthotopic mouse model. Endocr. Relat. Cancer 2019. [CrossRef]

9. Lin, H.Y.; Landersdorfer, C.B.; London, D.; Meng, R.; Lim, C.U.; Lin, C.; Lin, S.; Tang, H.Y.; Brown, D.; Van Scoy, B.; et al. Pharmacodynamic modeling of anti-cancer activity of tetraiodothyroacetic acid in a perfused cell culture system. PLoS Comput. Biol. 2011, 7, e1001073. [CrossRef]

10. Chin, Y.T.; He, Z.R.; Chen, C.L.; Chu, H.C.; Ho, Y.; Su, P.Y.; Yang, Y.S.H.; Wang, K.; Shih, Y.J.; Chen, Y.R.; et al. Tetrac and ndat induce anti-proliferation via integrin $\alpha \mathrm{v} \beta 3$ in colorectal cancers with different k-ras status. Front. Endocrinol. 2019, 10, 130. [CrossRef] [PubMed]

11. Lee, Y.S.; Chin, Y.T.; Yang, Y.S.H.; Wei, P.L.; Wu, H.C.; Shih, A.; Lu, Y.T.; Pedersen, J.Z.; Incerpi, S.; Liu, L.F.; et al. The combination of tetraiodothyroacetic acid and cetuximab inhibits cell proliferation in colorectal cancers with different k-ras status. Steroids 2016, 111, 63-70. [CrossRef] [PubMed]

12. Chang, T.C.; Chin, Y.T.; Nana, A.W.; Wang, S.H.; Liao, Y.M.; Chen, Y.R.; Shih, Y.J.; Changou, C.A.; Yang, Y.S.; Wang, K.; et al. Enhancement by nano-diamino-tetrac of antiproliferative action of gefitinib on colorectal cancer cells: Mediation by egfr sialylation and pi3k activation. Horm. Cancer 2018, 9, 420-432. [CrossRef] [PubMed]

13. Schmohl, K.A.; Müller, A.M.; Wechselberger, A.; Rühland, S.; Salb, N.; Schwenk, N.; Heuer, H.; Carlsen, J.; Göke, B.; Nelson, P.J.; et al. Thyroid hormones and tetrac: New regulators of tumour stroma formation via integrin $\alpha \mathrm{v} \beta 3$. Endocr. Relat. Cancer 2015, 22, 941-952. [CrossRef] [PubMed]

14. Chen, Y.R.; Chen, Y.S.; Chin, Y.T.; Li, Z.L.; Shih, Y.J.; Yang, Y.S.H.; ChangOu, C.A.; Su, P.Y.; Wang, S.H.; Wu, Y.H.; et al. Thyroid hormone-induced expression of inflammatory cytokines interfere with resveratrol-induced anti-proliferation of oral cancer cells. Food Chem. Toxicol. Int. J. Publ. Br. Ind. Biol. Res. Assoc. 2019, 132, 110693. [CrossRef]

15. Ho, Y.; Wu, C.Y.; Chin, Y.T.; Li, Z.L.; Pan, Y.S.; Huang, T.Y.; Su, P.Y.; Lee, S.Y.; Crawford, D.R.; Su, K.W.; et al. Ndat suppresses pro-inflammatory gene expression to enhance resveratrol-induced anti-proliferation in oral cancer cells. Food Chem. Toxicol. Int. J. Publ. Br. Ind. Biol. Res. Assoc. 2020, 136, 111092. [CrossRef]

16. Davis, P.J.; Glinsky, G.V.; Lin, H.Y.; Incerpi, S.; Davis, F.B.; Mousa, S.A.; Tang, H.Y.; Hercbergs, A.; Luidens, M.K. Molecular mechanisms of actions of formulations of the thyroid hormone analogue, tetrac, on the inflammatory response. Endocr. Res. 2013, 38, 112-118. [CrossRef]

17. Lin, H.Y.; Chin, Y.T.; Yang, Y.C.; Lai, H.Y.; Wang-Peng, J.; Liu, L.F.; Tang, H.Y.; Davis, P.J. Thyroid hormone, cancer, and apoptosis. Compr. Physiol. 2016, 6, 1221-1237.

18. Lin, H.Y.; Davis, P.J.; Tang, H.Y.; Mousa, S.A.; Luidens, M.K.; Hercbergs, A.H.; Davis, F.B. The pro-apoptotic action of stilbene-induced cox-2 in cancer cells: Convergence with the anti-apoptotic effect of thyroid hormone. Cell Cycle (Georget. Tex.) 2009, 8, 1877-1882. [CrossRef]

19. Pal, S.K.; Nguyen, C.T.; Morita, K.I.; Miki, Y.; Kayamori, K.; Yamaguchi, A.; Sakamoto, K. Thbs1 is induced by $\operatorname{tgfb} 1$ in the cancer stroma and promotes invasion of oral squamous cell carcinoma. J. Oral Pathol. Med. Off. Publ. Int. Assoc. Oral Pathol. Am. Acad. Oral Pathol. 2016, 45, 730-739. [CrossRef]

20. Lin, H.Y.; Delmas, D.; Vang, O.; Hsieh, T.C.; Lin, S.; Cheng, G.Y.; Chiang, H.L.; Chen, C.E.; Tang, H.Y.; Crawford, D.R.; et al. Mechanisms of ceramide-induced cox-2-dependent apoptosis in human ovarian cancer ovcar-3 cells partially overlapped with resveratrol. J. Cell. Biochem. 2013, 114, 1940-1954. [CrossRef] 
21. Glinskii, A.B.; Glinsky, G.V.; Lin, H.Y.; Tang, H.Y.; Sun, M.; Davis, F.B.; Luidens, M.K.; Mousa, S.A.; Hercbergs, A.H.; Davis, P.J. Modification of survival pathway gene expression in human breast cancer cells by tetraiodothyroacetic acid (tetrac). Cell Cycle (Georget. Tex.) 2009, 8, 3562-3570. [CrossRef] [PubMed]

22. Yalcin, M.; Dyskin, E.; Lansing, L.; Bharali, D.J.; Mousa, S.S.; Bridoux, A.; Hercbergs, A.H.; Lin, H.Y.; Davis, F.B.; Glinsky, G.V.; et al. Tetraiodothyroacetic acid (tetrac) and nanoparticulate tetrac arrest growth of medullary carcinoma of the thyroid. J. Clin. Endocrinol. Metab. 2010, 95, 1972-1980. [CrossRef]

23. Yalcin, M.; Lin, H.Y.; Sudha, T.; Bharali, D.J.; Meng, R.; Tang, H.Y.; Davis, F.B.; Stain, S.C.; Davis, P.J.; Mousa, S.A. Response of human pancreatic cancer cell xenografts to tetraiodothyroacetic acid nanoparticles. Horm. Cancer 2013, 4, 176-185. [CrossRef]

24. Yang, S.H.; Lin, H.Y.; Changou, C.A.; Chen, C.H.; Liu, Y.R.; Wang, J.; Jiang, X.; Luh, F.; Yen, Y. Integrin beta3 and $1 \mathrm{~kb} 1$ are independently involved in the inhibition of proliferation by lovastatin in human intrahepatic cholangiocarcinoma. Oncotarget 2016, 7, 362-373. [CrossRef] [PubMed]

25. Zhang, Y.E. Non-smad pathways in tgf-beta signaling. Cell Res. 2009, 19, 128-139. [CrossRef] [PubMed]

26. Massague, J. Tgfbeta in cancer. Cell 2008, 134, 215-230. [CrossRef] [PubMed]

27. Elston, R.; Inman, G.J. Crosstalk between p53 and tgf-beta signalling. J. Signal Transduct. 2012, $2012,294097$. [CrossRef] [PubMed]

28. Inman, G.J. Switching tgfbeta from a tumor suppressor to a tumor promoter. Curr. Opin. Genet. Dev. 2011, 21, 93-99. [CrossRef]

29. Meulmeester, E.; Ten Dijke, P. The dynamic roles of tgf-beta in cancer. J. Pathol. 2011, 223, 205-218. [CrossRef] [PubMed]

30. Huang, T.; David, L.; Mendoza, V.; Yang, Y.; Villarreal, M.; De, K.; Sun, L.; Fang, X.; Lopez-Casillas, F.; Wrana, J.L.; et al. Tgf-beta signalling is mediated by two autonomously functioning tbetari:Tbetarii pairs. EMBO J. 2011, 30, 1263-1276. [CrossRef]

31. Massague, J. A very private tgf-beta receptor embrace. Mol. Cell 2008, 29, 149-150. [CrossRef] [PubMed]

32. Groppe, J.; Hinck, C.S.; Samavarchi-Tehrani, P.; Zubieta, C.; Schuermann, J.P.; Taylor, A.B.; Schwarz, P.M.; Wrana, J.L.; Hinck, A.P. Cooperative assembly of tgf-beta superfamily signaling complexes is mediated by two disparate mechanisms and distinct modes of receptor binding. Mol. Cell 2008, 29, 157-168. [CrossRef] [PubMed]

33. Massague, J.; Seoane, J.; Wotton, D. Smad transcription factors. Genes Dev. 2005, 19, 2783-2810. [CrossRef] [PubMed]

34. Heldin, C.H.; Moustakas, A. Role of smads in tgfbeta signaling. Cell Tissue Res. 2012, 347, 21-36. [CrossRef]

35. Liu, S.; Chen, S.; Zeng, J. Tgfbeta signaling: A complex role in tumorigenesis (review). Mol. Med. Rep. 2018, 17,699-704.

36. Wyllie, F.S.; Dawson, T.; Bond, J.A.; Goretzki, P.; Game, S.; Prime, S.; Wynford-Thomas, D. Correlated abnormalities of transforming growth factor-beta 1 response and p53 expression in thyroid epithelial cell transformation. Mol. Cell. Endocrinol. 1991, 76, 13-21. [CrossRef]

37. Cordenonsi, M.; Dupont, S.; Maretto, S.; Insinga, A.; Imbriano, C.; Piccolo, S. Links between tumor suppressors: P53 is required for tgf-beta gene responses by cooperating with smads. Cell 2003, 113, 301-314. [CrossRef]

38. Takebayashi-Suzuki, K.; Funami, J.; Tokumori, D.; Saito, A.; Watabe, T.; Miyazono, K.; Kanda, A.; Suzuki, A. Interplay between the tumor suppressor p53 and tgf beta signaling shapes embryonic body axes in xenopus. Dev. (Camb. Engl.) 2003, 130, 3929-3939. [CrossRef]

39. Chen, X.; Weisberg, E.; Fridmacher, V.; Watanabe, M.; Naco, G.; Whitman, M. Smad4 and fast-1 in the assembly of activin-responsive factor. Nature 1997, 389, 85-89. [CrossRef]

40. Cordenonsi, M.; Montagner, M.; Adorno, M.; Zacchigna, L.; Martello, G.; Mamidi, A.; Soligo, S.; Dupont, S.; Piccolo, S. Integration of tgf-beta and ras/mapk signaling through p53 phosphorylation. Science (N. Y. NY) 2007, 315, 840-843. [CrossRef]

41. Dupont, S.; Zacchigna, L.; Adorno, M.; Soligo, S.; Volpin, D.; Piccolo, S.; Cordenonsi, M. Convergence of p53 and tgf-beta signaling networks. Cancer Lett. 2004, 213, 129-138. [CrossRef] [PubMed] 
42. Yang, C.Y.; Meng, C.L. Regulation of pg synthase by egf and pdgf in human oral, breast, stomach, and fibrosarcoma cancer cell lines. J. Dent. Res. 1994, 73, 1407-1415. [CrossRef] [PubMed]

43. Chin, Y.T.; Hsieh, M.T.; Lin, C.Y.; Kuo, P.J.; Yang, Y.C.; Shih, Y.J.; Lai, H.Y.; Cheng, G.Y.; Tang, H.Y.; Lee, C.C.; et al. 2,3,5,4'-tetrahydroxystilbene-2-o-beta-glucoside isolated from polygoni multiflori ameliorates the development of periodontitis. Mediat. Inflamm. 2016, 2016, 6953459. [CrossRef] [PubMed]

44. Lin, H.Y.; Chin, Y.T.; Nana, A.W.; Shih, Y.J.; Lai, H.Y.; Tang, H.Y.; Leinung, M.; Mousa, S.A.; Davis, P.J. Actions of 1-thyroxine and nano-diamino-tetrac (nanotetrac) on pd-11 in cancer cells. Steroids 2016, 114, $59-67$. [CrossRef]

(C) 2020 by the authors. Licensee MDPI, Basel, Switzerland. This article is an open access article distributed under the terms and conditions of the Creative Commons Attribution (CC BY) license (http://creativecommons.org/licenses/by/4.0/). 